중심망막동맥폐쇄로 진단된 환자들의 장기 임상결과와 예후 닌

\title{
Long-term Clinical Outcomes and Prognostic Factors of Patients Diagnosed with Central Retinal Artery Occlusion
}

\author{
황재형, 임수현, 김철구, 김종우, 김재휘 \\ Jae Hyeong Hwang, Su Hyun Lim, Chul Gu Kim, Jong Woo Kim, Jae Hui Kim \\ 김안과병원 \\ Kim's Eye Hospital, Seoul, Korea
}

Purpose: To evaluate long-term clinical outcomes of patients with central retinal artery occlusion and to investigate factors associated with visual recovery.

Methods: This retrospective study was performed on 31 patients with central retinal artery occlusion. The patients were divided into 3 groups according to degree of vascular occlusion: incomplete, subtotal, total. Visual acuity was classified as finger counting or worse, 0.02 or better and worse than 0.1 , and 0.1 or better. The proportions of patients in these 3 groups at diagnosis were compared to those at the final follow-up. In addition, factors associated with visual recovery were investigated.

Results: The mean follow-up period was $40.0 \pm 22.0$ months. According to degree of vascular occlusion, 10 patients were incomplete, 17 were subtotal, and 4 were total. During the follow-up period, visual acuity was recovered in 14 patients, maintained in 6, and deteriorated in 11. At diagnosis, visual acuity was finger counting or worse in $77.4 \%$ of patients, 0.02 or better and worse than 0.1 in $22.6 \%$, and 0.1 or better in 0 . At the final visit, these proportions changed to $58.1 \%, 22.6 \%$, and $19.4 \%(p=0.013)$, respectively. Visual recovery was limited with greater degree of occlusion $(p=0.004)$.

Conclusions: During the follow-up period, visual recovery was noted in $45 \%$ of patients with central retinal artery occlusion. Degree of vascular occlusion was identified as a factor predictive of visual recovery.

Keywords: Central retinal artery occlusion; Long-term; Outcome

서론

중심망막동맥폐쇄는 동통 없이 갑작스러운 시력상실을 유발하 는 질환으로 1 년에 10 만 명 당 약 1.8 명에서 발생하는 비교적 드 문 질환이다[1]. 특히 80세 이상의 고령에서 그 발생률이 높은
것으로 알려져 있다[1]. 중심망막동맥폐쇄가 발생하면 허혈에 의한 망막세포의 손상이 발생하게 되는데, 특히 동맥폐쇄 이후 4시간 이상 경과하는 경우 비가역적인 심한 손상이 나타나는 것으로 보고되었다[2].

중심망막동맥폐쇄의 예후는 보통 좋지 않은 것으로 알려져

\section{Address reprint requests to Jae Hui Kim, MD}

Kim's Eye Hospital, \#136 Yeongsin-ro, Yeongdeungpo-gu, Seoul 07301, Korea

Tel: 82-2-2639-7664, Fax: 82-2-2639-7824

E-mail:kjh7997@daum.net
Received: 2021. 2. 15

Revised: 2021. 3. 20.

Accepted: 2021. 3. 29. 
있다[3-6]. 현재까지 전방천자술, 안구마사지, 고농도산소치료, 경구 아세타졸아마이드 및 아스피린 투여, 혈전용해술 등의 방 법을 통해 일부 환자에서 시력호전을 기대할 수 있는 것으로 보 고되었으나[3,7,8] 아직 질환을 확실하게 치료할 수 있는 방법은 없는 상태이다.

중심망막동맥폐쇄에 대한 국내 보고의 경우 1968년 $\mathrm{Oh}$ and Kim [9]의 증례보고가 최초 보고이다. 이후 1989년 Kim et al. [6]이 19안의 임상경과를 분석하여 보고하였으며, 1996년 Min [10]은 불완전 중심망막동맥폐쇄 5안의 임상경과를 보고하였다. 이후에도 여러 연구들이 있었으나 대부분 증례보고의 형식이 었다. 국내 보고 중 가장 많은 안을 대상으로 한 Kim et al. [6] 의 연구의 경우 추적 관찰 기간이 2주에서 3년 사이로 환자 간 에 편차가 커 장기 임상 경과를 정확하게 확인하기에는 어려운 면이 있으며, 빛간섭단층촬영을 시행하지 않았다. 국내 환자 133 명을 대상으로 한 연구 결과를 해외학술지에 보고한 Ahn et al. [11]의 연구의 경우 평균 추적 관찰 기간이 11 개월로 비교적 짧았다. 본 연구에서는 중심망막동맥폐쇄 31안을 대상으로 평 균 약 40개월 동안 장기 경과 관찰한 결과를 확인하고, 시력회 복과 연관된 인자들을 분석하고자 한다.

\section{대상과 방법}

본 후향적 연구는 단일 기관에서 헬싱키 선언에 입각하여 시행 되었으며, Institutional Review Board (IRB) 승인을 획득하였다 (Kim's Eye Hospital IRB, No. 2020-12-008). 2011년 1월 1일부터
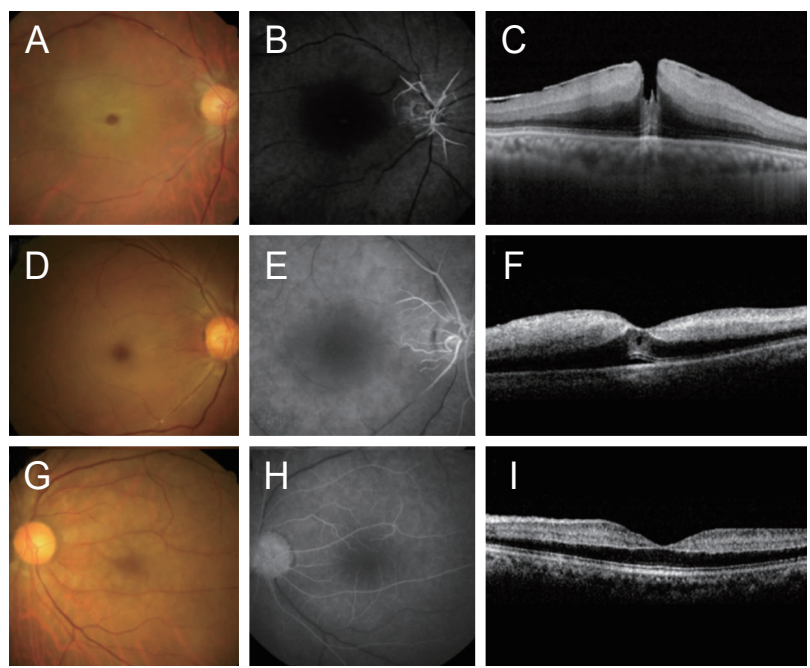

Figure 1. Representative images showing total (A-C), subtotal (D-F), and incomplete (G-I) central retinal artery occlusion. Note the marked increase in retinal edema and distinct cherry-red spots in total occlusion (A) compared to subtotal (D) or incomplete (G) occlusion.
2015년 12월 31일 사이에 중심망막동맥폐쇄로 진단받은 환자들 중 진단 후 12 개월 이상 추적 관찰한 경우를 연구에 포함하였 다. 증상 기간이 7일을 초과한 경우, 중심망막동맥폐쇄 진단 이 전에 유리체망막수술을 시행 받은 병력이 있는 경우, 유리체출 혈에 의해 최종 망막 상태를 확인하기 어려웠던 경우는 연구에 서 제외하였다. 이전에 녹내장이나 황반변성, 증식당뇨망막병증 의 과거력이 있던 경우 역시 연구에서 제외하였다.

모든 환자에서 진단 시 세극등검사, 안저검사 및 최대교정시 력 측정을 시행했으며, 추가적으로 안저촬영, 형광안저혈관조 영술 및 빛간섭단층촬영을 시행했다. 빛간섭단층촬영에는 3종 류의 기기가 이용되었다: Spectralis HRA-OCT TM (Heidelberg Engineering, Heidelberg, Germany), RS 3000 ${ }^{\mathrm{TM}}$ (Nidek Co., Ltd., Tokyo, Japan), or SLO-OCT ${ }^{\mathrm{TM}}$ (OTI Ophthalmic Technologies Inc, Toronto, Canada). 진단 후 의사의 판단에 따 라 안구마사지, 전방천자, 안압하강제 등의 치료가 시행되었으 며, 특별한 치료 없이 경과 관찰한 경우도 있었다.

중심망막동맥폐쇄는 임상 소견과 형광안저혈관조영술 결과 를 바탕으로 불완전폐쇄(incomplete), 부분폐쇄(subtotal), 전체 폐쇄(total)의 3단계로 구분하였다(Fig. 1) [11,12]: 불완전폐쇄(망 막부종과 함께 앵두반점(cherry-red spot)이 없거나 희미하게 보 이며, 시력은 부분적으로 감소되어 있고, 형광안저혈관조영술 에서 경도의 망막동맥 혈류 지연이 관찰되나 완전한 혈류의 차 단은 나타나지 않는 경우), 부분폐쇄(뚜렷한 망막부종과 앵두반 점이 관찰되고 심한 시력저하가 나타나며, 형광안저혈관조영술 에서 뚜렷한 혈류의 지연, 특히 황반부 망막소동맥의 혈류 지연 과 함께 일부 혈류의 차단이 관찰되는 경우), 전체폐쇄(앵두반 점을 동반하는 광범위하고 심한 망막부종이 관찰되고 시력은 심하게 저하되었으며, 형광안저혈관조영술에서 초기의 맥락막 충만을 포함한 혈류가 관찰되지 않는 경우). 추가적으로 빛간섭 단층촬영 결과를 분석하여 뚜렷한 중간경계막 징후(prominent middle limiting membrane sign) [13] 유무를 확인하였다(Fig. 2).

진단 시 및 최종 추적 관찰 시 측정된 최대교정시력을 기록하

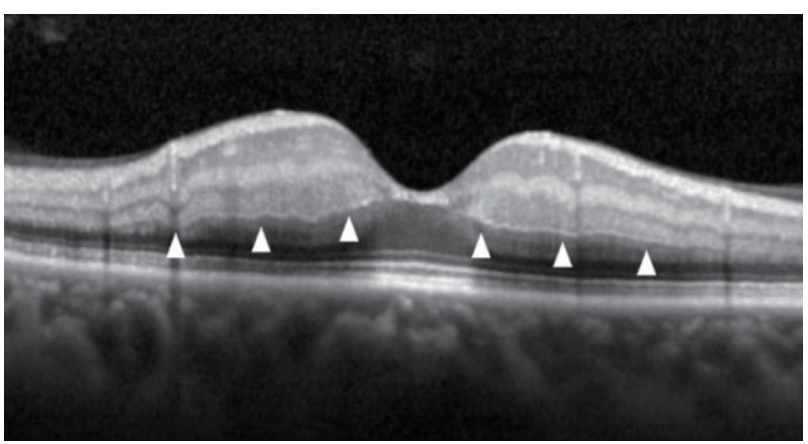

Figure 2. An optical coherence tomography image of an eye with central retinal artery occlusion. Arrowheads indicate a prominent middle limiting membrane. 
였다. 추가적으로 빛간섭단층촬영 사진을 이용하여 중심망막 두께를 측정하였는데, 중심와 부위에서 내경계막으로부터 부 르크막(Bruch's membrane)까지의 수직 거리를 중심망막두께로 정의하였다.

시력을 안전수지(counting finger) 이하, 0.02 이상 0.1 미만, 0.1 이상의 세 군으로 구분하여 진단 시 및 최종추적 관찰 시 각 군의 비율 차이를 확인하였다. 진단 시 측정된 중심망막두 께를 최종추적 관찰 시 측정된 값과 서로 비교하였는데, 상기 비교의 경우 최종추적 관찰 시 빛간섭단층촬영을 시행한 환 자만을 대상으로 시행하였다. 또한 시력회복과 관련된 인자를 확인하기 위해 전체 환자들을 추적 관찰 기간 중 시력이 호전 된 경우와 유지 혹은 악화된 경우의 두 군으로 나누었으며, 아 래와 같은 인자와의 연관성을 분석하였다: 나이(75세 미만 vs. 75세 이상), 성별(남성 vs. 여성), 당뇨병 유무, 고혈압 유무, 증 상 기간(2일 이하 vs. 2일 초과), 추적 관찰 기간(36개월 미만 vs 36 개월 이상), 치료 여부, 폐쇄 정도(불완전폐쇄 vs. 부분폐쇄 vs. 전체폐쇄), 뚜렷한 중간경계막 징후 여부, 최대교정시력(안 전수지 시력 이상 vs. 안전수지 시력 미만), 중심망막두께( $<260$ $\mu \mathrm{m}$ vs. $\geq 260 \mu \mathrm{m})$.

본 연구에서 심초음파와 같은 전신적인 검사의 경우 타병원으 로 의뢰하여 시행하였다. 경동맥 도플러(carotid doppler) 검사의 경우 의사의 판단에 따라 본원에서 시행한 경우도 있었다. 본원 에서 시행하였던 경동맥 도플러 검사상 혈전(plaque)이나 협착 (stenosis)이 발견된 경우와 그렇지 않았던 경우로 구분하여 최 종 시력과 시력호전이 나타난 비율을 서로 비교하였다.

통계 분석에는 SPSS 프로그램(SPSS ver. 12.0 for Windows; IBM Corp., Armonk, NY, USA)을 이용하였다. Paired $t$-test를 이용하여 서로 다른 두 시점에 측정된 값을 비교하였으며, 서 로 다른 군 사이의 비교는 Mann-Whitney $U$ test 혹은 Fisher's exact test를 이용하였다. 시력회복과 관련된 인자 분석에는 binary logistic regression을 이용하였다. 0.05 미만의 $p$ 값을 통 계적으로 유의한 값으로 정의하였다.

\section{결과}

연구 포함 기준을 만족시킨 35 명 중 증상 기간이 7일을 초과 한 경우 2 명, 중심망막동맥폐쇄 진단 이전에 유리체망막수술 을 시행 받은 병력이 있는 경우 1 명, 유리체출혈에 의해 최종 망막 상태를 확인하기 어려웠던 경우 1 명이 연구에서 제외되었 다. 결과적으로 전체 31 명(31안)을 대상으로 연구를 시행하였다 (Table 1). 평균 연령은 $73.4 \pm 10.7$ 세였으며, 평균 추적 관찰 기 간은 $40.0 \pm 22.0$ 개월이었다. 폐쇄 정도에 따라 구분하였을 때, 10 명(32.3\%)이 불완전폐쇄, 17명(54.8\%)이 부분폐쇄, 4 명(12.9\%)이 전체폐쇄로 확인되었다. 뚜렷한 중간경계막 징후는 20명(64.5\%)에
서 관찰되었으며, 5명(16.1\%)에서 섬모체망막동맥(cilioretinal artery) 이 보존된 소견이 나타났다.

중심망막동맥폐쇄 진단 직후 22명(70.9\%)은 치료를 시행 받 았으며, 치료 방식은 다음과 같았다: 전방천자 시행(2명), 안구 마사지 시행(2명), 안압하강제 점안(13명), 안구마사지 시행 및 안압하강제 점안(2안), 안구마사지, 전방천자, 안압하강제 점안 시행(3명). 9 명(29.1\%)의 경우 특별한 치료 없이 경과 관찰하였 다. 추적 관찰 기간 중 6명(19.4\%)에서 평균 $6.0 \pm 7.3$ 주에 안 내 신생혈관(ocular neovascularization)의 발생이 관찰되었 는데, 6 안 모두에서 5 개월 이내에 신생혈관이 관찰되었다. 이 들 중 4명(12.9\%)의 경우 안압상승이 나타나 신생혈관녹내장으 로 진단되었다.

추적 관찰 기간 중 14 명(45.2\%)에서 시력이 회복되었고, 6 명 (19.4\%)에서 시력이 유지되었으며, 11명(35.5\%)에서 시력이 악화 되었다. 진단 당시의 시력은 안전수지 이하가 24명(77.4\%), 0.02 이상 0.1 미만이 7명(22.6\%)이었으며, 0.1 이상은 없었다. 최종추 적 관찰 시에는 안전수지 이하가 18 명 $(58.1 \%), 0.02$ 이상 0.1 미 만이 7명(22.6\%)이었으며, 0.1 이상이 6명(19.4\%)이었다. 진단 시 와 최종추적 관찰 시 각 시력군에 속한 환자 비율에는 유의한 차이가 있었다 $(p=0.013)$. 최종추적 관찰 시의 평균 logarithm of minimal angle of resolution ( $\log$ MAR) 시력은 불완전폐쇄에 서 $1.42 \pm 0.81$, 부분폐쇄에서 $2.24 \pm 0.77$, 전체폐쇄에서 2.78 \pm 0.05 로 측정되었다.

Table 1. Characteristics of the study population $(n=31)$

\begin{tabular}{lc}
\hline Characteristic & Value \\
\hline Age (years) & $73.4 \pm 10.7$ \\
Sex (male:female) & $25(80.6): 6(19.4)$ \\
Diabetes mellitus & $13(41.9)$ \\
Hypertension & $22(70.9)$ \\
History of coronary artery disease & $3(9.7)$ \\
History of stroke & $5(16.1)$ \\
Duration of symptoms (days) & $2.9 \pm 2.2$ \\
Follow-up period (months) & $40.0 \pm 22.0$ \\
Treatment & $22(70.9)$ \\
Degree of occlusion & \\
$\quad$ Incomplete & $10(32.3)$ \\
Subtotal & $17(54.8)$ \\
Total & $4(12.9)$ \\
Prominent middle limiting membrane sign & $20(64.5)$ \\
Cilioretinal artery sparing & $5(16.1)$ \\
Best-corrected visual acuity (logMAR) & $2.42 \pm 0.47$ \\
Central foveal thickness ( $\mu$ m) & $300.3 \pm 75.0$ \\
\hline
\end{tabular}

Values are presented as mean \pm standard deviation or number (\%), $\log M A R=$ logarithm of minimal angle of resolution. 
진단 시 및 최종추적 관찰 시의 중심망막두께 비교는 최종추 적 관찰 시 빛간섭단층촬영을 시행하였던 29명을 대상으로 시 행되었다. 평균 중심망막두께는 진단 시 $300.3 \pm 75.0 \mu \mathrm{m}$ 였으 며, 최종 추적 관찰 시 $194.8 \pm 31.1 \mu \mathrm{m}$ 로 유의하게 감소하였다 $(p<0.001)$. 불완전폐쇄로 분류된 10 명 중 경과 관찰 기간 동안 재발을 보인 경우는 없었다.

시력회복과 관련된 인자 분석에서 혈관 폐쇄 정도가 장기 시 력회복과 유의하게 관련된 인자로 나타났다(Table 2, $p=0.004)$. 불완전폐쇄의 경우 시력이 회복된 경우가 8 명(80.0\%), 시력이 유 지되거나 악화된 경우가 2명(20.0\%)이었으며(Fig. 3), 부분폐쇄 의 경우 각각 6 명(35.3\%) 및 11 명(64.7\%), 전체폐쇄의 경우 각각 0명 및 4명(100\%)으로 폐쇄의 정도가 높을수록 시력이 회복 되는 비율이 뚜렷하게 더 낮았다. 나머지 인자들인 나이 $(p=$ $0.324)$, 성별 $(p=0.467)$, 당뇨 $(p=0.909)$, 고혈압 $(p=0.694)$, 증 상 기간 $(p=0.314)$, 추적 관찰 기간 $(p=0.984)$, 치료 여부 $(p=$ $0.328)$, 뚜렷한 중간경계막 징후 여부 $(p=0.086)$, 최대교정시력 $(p=0.778)$, 중심망막두께 $(p=0.496)$ 의 경우 시력회복과 유의한 관련성이 나타나지 않았다.

경동맥 도플러 검사는 15 명에서 시행하였는데, 이들 중 10 명 에서 경동맥의 혈전 혹은 협착이 발견되었다. 혈전이나 협착이 발견된 환자와 상기 이상이 발견되지 않았던 환자에서 최종추 적 관찰 시의 최대교정시력은 각각 평균 $\log M A R ~ 2.20 \pm 0.67$, $1.84 \pm 0.80$ 으로 측정되었으며, 양 군 사이에 유의한 차이는 없었다 $(p=0.371)$. 시력이 호전된 비율은 혈전이나 협착이 발 견된 환자에서 $40.0 \%$, 상기 이상이 발견되지 않았던 환자에서 $60.0 \%$ 였다.

Table 2. Association of characteristics with visual recovery

\begin{tabular}{lcc}
\hline Characteristics $^{+}$ & $p^{\text {-value }}{ }^{*}$ & $\beta$ \\
\hline Age $^{\dagger}$ & 0.324 & \\
Sex $^{\dagger}$ & 0.467 & \\
Diabetes mellitus $^{\dagger}$ & 0.909 & \\
Hypertension $^{\dagger}$ & 0.694 & \\
Duration of symptoms $^{\dagger}$ & 0.314 & \\
Follow-up period $^{\dagger}$ & 0.984 & \\
Treatment $^{\text {Degree of occlusion }}{ }^{\dagger}$ & 0.328 & \\
Prominent middle limiting membrane sign $^{\dagger}$ & 0.004 & 7.333 \\
Best-corrected visual acuity (logMAR) $^{\dagger}$ & 0.086 & \\
Central foveal thickness $^{\dagger}$ & 0.778 & \\
\hline
\end{tabular}

logMAR = logarithm of minimal angle of resolution.

${ }^{*}$ Statistical analysis with binary logistic regression; ${ }^{\dagger}$ Characteristics were identified at baseline.
고찰

Hayreh and Zimmerman [4]의 연구에서 비동맥염성(nonarteritic) 중심망막동맥폐쇄의 경우 $87.7 \%$ 에서 진단 시 안전 수지 이하의 시력을 보였다. 경과 관찰 후 상기 비율은 $79.5 \%$ 로 낮아지기는 하였으나 여전히 대부분의 안에서 시력회복 이 제한적인 소견을 보였다. 그러나 일시적인(transient) 중심 망막동맥폐쇄의 경우에 보다 나은 시력 결과를 보였는데, 진 단 시 안전수지 이하의 시력을 보인 안은 $34.1 \%$ 였으며, 경 과 관찰 후 상기 비율은 $13.2 \%$ 로 낮아지는 결과를 보였다 [4]. Kim et al. [6]은 망막동맥폐쇄로 진단된 35안의 임상 경 과를 국내 보고하였는데, 이 중 19안이 중심망막동맥폐쇄 였다. 환자의 연령은 60대가 47.4\%로 가장 많았으며, $31.6 \%$ 에서 고혈압, $10.5 \%$ 에서 당뇨병, $15.8 \%$ 에서 심장질환을 동 반하고 있었다. 시력의 경우 진단 시 전체 19 안 모두 안전수 지 이하였는데, 최종 추적 관찰 시 안전수지보다 더 나은 시 력으로 회복된 경우는 1 안에 불과하였다. Min [10]은 불완전 망막중심동맥폐쇄 5 안의 임상 경과를 보고하였다. 초진 당시 5 안 모두 시력은 0.1 미만이었으며, 4 안에서는 시력호전이 나타 나지 않았다. 그러나 1 안의 경우 초진 당시 0.07 이었던 시력이 최 종 추적 관찰 시에는 1.2 로 큰 폭으로 호전되는 양상을 보였다.

국내 환자 133 명을 대상으로 평균 11.7 개월 경과 관찰한 $\mathrm{Ahn}$ et al. [11]의 연구에서는 동맥폐쇄의 정도를 불완전폐쇄(25.4\%), 부분폐쇄(58.2\%), 전체폐쇄(16.4\%)의 3단계로 나누어 해부학적 결과를 분석하였는데, 폐쇄가 심할수록 최초 진단 시 망막이 더 두꺼웠으며, 최종 추적 관찰 시의 망막이 더 얇은 결과를 보 였다. 최종 추적 관찰 시의 중심와 부위 시세포층의 결손의 경

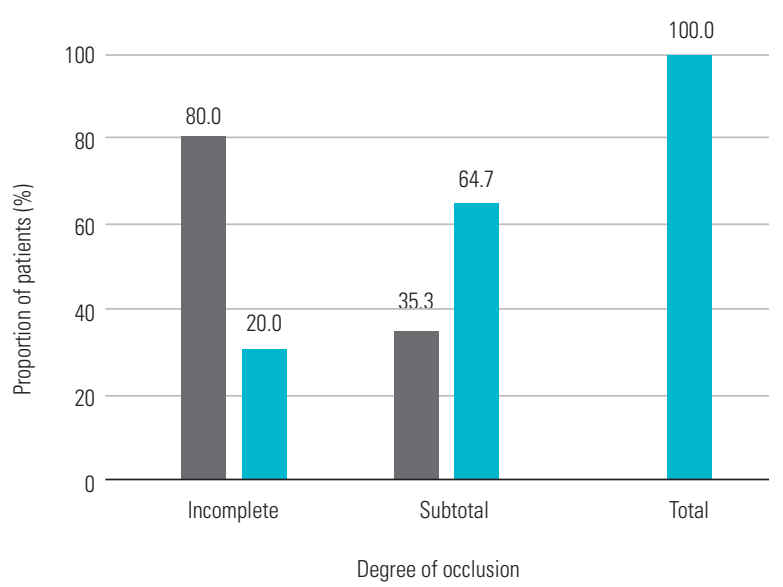

Figure 3. Proportions of patients with and without visual recovery during follow-up according to degree of occlusion. Dark gray bars indicate patients with visual recovery, whereas blue bars indicate patients with the same or deterioration in visual acuity. 
우 폐쇄가 심할수록 더 높은 빈도로 나타났다. 그러나 진단 시 관찰되는 뚜렷한 중간경계막 징후의 경우 반대로 폐쇄의 정도 가 심할수록 더 그 빈도가 더 낮은 경향을 보였다.

본 연구에서는 진단 시 대부분의 환자에서 안전수지 이하의 시력을 보였으나 일부에서 시력회복이 나타나면서 최종 추적 관 찰 시에는 안전수지 이하의 시력을 보인 환자의 비율이 뚜렷하 게 감소하였다. 본 연구에서 나타난 불완전폐쇄, 부분폐쇄, 전 체폐쇄 단계의 빈도는 Ahn et al. [11]의 연구와 비슷한 결과를 보였다. 폐쇄의 정도가 심할수록 시력이 회복되는 빈도가 뚜렷 하게 낮아지는 경향을 보였는데, 불완전폐쇄 단계의 경우 $80 \%$ 라는 비교적 높은 빈도로 시력회복이 나타났으나 전체폐쇄 단 계의 경우 시력회복이 나타난 경우가 없었다. 시력회복 여부를 예측할 수 있는 인자 분석에서 폐쇄의 정도는 시력회복과 가장 밀접하게 관련된 인자로 나타났다.

스펙트럼영역 빛간섭단층촬영 기기의 도입과 함께 중심망막 동맥폐쇄에서 망막 각 층에 나타나는 다양한 변화가 알려지게 되었다. Matthé et al. [14]의 연구에서는 중심망막동맥폐쇄 안 에서 망막의 내층 및 중간층의 두께가 뚜렷하게 증가하는 것 으로 나타났는데, 이러한 두께 증가는 폐쇄의 정도가 심할수 록 더 크게 나타나는 경향이 있었다. Ahn et al. [11]의 연구에 서는 더 심하게 혈관이 폐쇄된 상태일수록 진단 시 황반부종이 더 뚜렷하게 나타났으며, 최종추적 관찰 시 망막이 더 얇아지 는 경향이 있었다. Kim et al. [15]은 중심망막동맥폐쇄 안에서 반대안에 비해 망막신경섬유층이 더 두꺼워지는 경향이 있었으 며, 양안 사이에 차이가 클수록 예후가 더 나쁘다고 보고하였 다. Chu et al. [13]은 중심망막동맥폐쇄 안에서 뚜렷한 중간경 계막 징후를 관찰할 수 있으며, 이는 망막의 급성 허혈성 손상 을 나타내는 지표가 될 수 있다고 보고하였다. 본 연구에서는 전체 환자의 $64.5 \%$ 에서 뚜렷한 중간경계막 징후가 관찰되었는 데, 이는 Chu et al. [13]의 연구에서와 비슷한 빈도였다. 그러나 다변량 분석에서 상기 소견과 시력회복 사이의 유의한 연관관 계는 나타나지 않았다.

중심망막동맥폐쇄는 신생혈관녹내장을 유발할 수 있는 것으 로 알려져 있다. Mason et al. [16]의 연구에서는 전체 환자의 $12.0 \%$ 에서 신생혈관녹내장이 발생하였다. Jung et al. [17]의 연 구에서는 전체 환자의 $10.9 \%$ 에서 진단 후 평균 3 개월에 홍채신 생혈관이 관찰되었으며, $6.4 \%$ 에서 신생혈관녹내장이 발생하였 다. Jung et al. [17]은 재관류가 실패하며 장기간 망막허혈 상태 가 지속된 결과 신생혈관녹내장이 발생한 것으로 추측하였다. 본 연구에 포함된 환자에서 나타난 안내 신생혈관은 모두 5 개 월 이내에 나타났는데, 이는 중심망막동맥폐쇄와 연관되어 발생 하는 안내 신생혈관이 대부분 4개월 이내에 발생한다는 Rudkin et al. [18]의 연구 결과와 일치하는 결과라 할 수 있다. 신생혈관 녹내장의 경우 전체의 $12.9 \%$ 에서 발생하여, Mason et al. [16]의 연구와 비슷한 발생 빈도를 보였다.
국내 환자를 대상으로 평균 11.7 개월 경과 관찰 결과를 분석 한 Ahn et al. [11]의 연구와 비교하였을 때, 본 연구의 환자들은 불완전폐쇄의 비율이 상대적으로 높았으며( $25.4 \%$ vs. $32.3 \%)$, 전 체폐쇄의 비율이 상대적으로 낮았다(16.4\% vs. $12.9 \%)$. 이와 같 은 결과는 본 연구가 12 개월 이상 추적 관찰한 환자만을 대상 으로 분석을 시행한 데에서 기인하였을 가능성이 있다. 최종 시 력의 경우 불완전폐쇄 군에서 평균 $\log$ MAR $1.15 \pm 0.67$, 부분 폐쇄 군에서 평균 $2.28 \pm 0.33$, 전체폐쇄 군에서 평균 $2.82 \pm$ 0.21 의 값을 보인 Ahn et al. [11]의 연구와 비교하였을 때, 본 연 구에서는 불완전폐쇄 군에서 조금 더 나쁜 시력을 보인 것을 제 외하면 전반적으로 비슷한 시력 결과가 나타났다.

본 연구의 제한점은 다음과 같다. 본 연구는 후향적 연구로 비교적 적은 수의 환자를 대상으로 시행되었다. 치료 여부 결정 에 있어서 명확한 기준이 없어 의사의 판단에 따라 다양한 치 료 방법이 이용되거나 치료 없이 경과 관찰을 시행하였다. 또 한 혈전용해술과 같은 적극적인 치료는 시행되지 않았다. 또한 12 개월 이상 경과 관찰한 환자만을 대상으로 결과를 분석하였 기에 선택편이(selection bias)가 결과에 영향을 미쳤을 가능성이 있다. 본 연구에서는 불완전폐쇄를 보였던 환자들 중 경과 관찰 중 재발한 경우가 없었는데, 엄격한 기준에 따라 자주 경과 관 찰하지 않았다는 점을 고려하였을 때, 경도 재발의 경우 확인하 지 못하였을 가능성을 배제할 수 없을 것이다. 중심망막동맥폐 쇄 환자는 다양한 전신 이상을 동반할 수 있는데, 본 연구에서 는 전체의 약 절반 정도에서만 경동맥 도플러 검사를 본원에서 시행하였으며, 다른 전신검사의 경우 타병원으로 검사를 의뢰 하였기에 전신 이상에 대하여 정확히 확인하기 어려웠다. 마지 막으로 진단 이후에는 반복적인 형광안저혈관조영술을 시행하 지 않아 혈관의 재관류 상태를 확인할 수 없었다.

요약하면 본 연구에서는 국내 중심망막동맥폐쇄 환자의 장기 임상결과를 분석하였다. 전체 환자의 약 $45 \%$ 에서 시력이 호전되 는 결과를 보였는데, 이러한 호전은 대부분 혈류폐쇄 정도가 심 하지 않았던 경우에서 나타났다. 안내 혈관신생은 5개월 이내에 주로 발생한다는 결과를 고려하였을 때, 상기 기간 동안 홍채신 생혈관의 발생이나 안압상승을 확인하는 데에 더욱 주의를 기 울여야 할 것으로 생각된다.

\section{Sources of Funding}

This work was supported by Kim's Eye Hospital Research Center.

\section{Conflicts of Interest}

The authors declare no conflicts of interest relevant to this article. 


\section{References}

1. Park SJ, Choi NK, Seo KH, et al. Nationwide incidence of clinically diagnosed central retinal artery occlusion in Korea, 2008 to 2011. Ophthalmology 2014;121:1933-8.

2. Hayreh SS, Zimmerman MB, Kimura A, Sanon A. Central retinal artery occlusion. Retinal survival time. Exp Eye Res 2004;78:72336.

3. Augsburger JJ, Magargal LE. Visual prognosis following treatment of acute central retinal artery obstruction. Br J Ophthalmol 1980;64:913-7.

4. Hayreh SS, Zimmerman MB. Central retinal artery occlusion: visual outcome. Am J Ophthalmol 2005;140:376-91.

5. Mueller AJ, Neubauer AS, Schaller U, et al. Evaluation of minimally invasive therapies and rationale for a prospective randomized trial to evaluate selective intra-arterial lysis for clinically complete central retinal artery occlusion. Arch Ophthalmol 2003;121:1377-81.

6. Kim YT, Yoon $I H$, Won IG. A clinical study of 35 cases of retinal artery occlusion. J Korean Ophthalmol Soc 1989;30:595-604.

7. Hwang G, Woo SJ, Jung C, et al. Intra-arterial thrombolysis for central retinal artery occlusion: two cases report. J Korean Med Sci 2010;25:974-9.

8. Dumitrascu OM, Newman NJ, Biousse V. Thrombolysis for central retinal artery occlusion in 2020: time is vision! J Neuroophthalmol 2020:40:333-45.

9. Oh TW, Kim CW. The successful treatment of a case of central retinal artery occlusion. J Korean Ophthalmol Soc 1968;9:31-3.
10. Min WK. Incomplete central retinal artery occlusion. J Korean Ophthalmol Soc 1996;37:782-9.

11. Ahn SJ, Woo SJ, Park KH, et al. Retinal and choroidal changes and visual outcome in central retinal artery occlusion: an optical coherence tomography study. Am J Ophthalmol 2015;159:667-76.

12. Schmidt DP, Schulte-Mönting J, Schumacher M. Prognosis of central retinal artery occlusion: local intraarterial fibrinolysis versus conservative treatment. AJNR Am J Neuroradiol 2002;23:1301-7.

13. Chu YK, Hong YT, Byeon SH, Kwon OW. In vivo detection of acute ischemic damages in retinal arterial occlusion with optical coherence tomography: a "prominent middle limiting membrane sign". Retina 2013;33:2110-7.

14. Matthé $E$, Eulitz $P$, Furashova $O$. Acute retinal ischemia in central versus branch retinal artery occlusion: changes in retinal layers' thickness on spectral-domain optical coherence tomography in different grades of retinal ischemia. Retina 2020;40:1118-23.

15. Kim H, Kim HK, Yang JY, Kim SS. Optical coherence tomography measurement and visual outcome in acute central retinal artery occlusion. Korean J Ophthalmol 2018;32:303-11.

16. Mason JO 3rd, Patel SA, Feist RM, et al. Ocular neovascularization in eyes with a central retinal artery occlusion or a branch retinal artery occlusion. Clin Ophthalmol 2015;9:995-1000.

17. Jung YH, Ahn SJ, Hong JH, et al. Incidence and clinical features of neovascularization of the iris following acute central retinal artery occlusion. Korean J Ophthalmol 2016;30:352-9.

18. Rudkin AK, Lee AW, Chen CS. Ocular neovascularization following central retinal artery occlusion: prevalence and timing of onset. Eur J Ophthalmol 2010;20:1042-6.

\section{국문초록}

\section{중심망막동맥폐쇄로 진단된 환자들의 장기 임상결과와 예후 인자}

목적: 중심망막동맥폐쇄 환자의 장기 임상 결과를 확인하고 시력회복과 연관된 인자들을 분석하고자 하였다.

대상과 방법: 중심망막동맥폐쇄로 진단받은 31 안을 대상으로 후향적 연구를 시행하였다. 전체 환자를 혈관폐쇄 정도에 따라 불완전폐 쇄, 부분폐쇄, 전체폐쇄의 세 군으로 구분하였다. 시력을 안전수지 이하, 0.02 이상/0.1 미만, 0.1 이상의 세 군으로 구분하여 진단 및 최종추적 관찰 시 각 군의 비율 차이를 확인하였다. 추가적으로 시력회복과 관련된 인자들을 분석하였다.

결과: 평균 추적 관찰 기간은 $40.0 \pm 22.0$ 개월이었으며, 불완전폐쇄 10 명, 부분폐쇄 17 명, 전체폐쇄 4 명이었다. 추적 관찰 중 14 명에 서 시력이 회복되었다. 진단 당시의 시력은 안전수지 이하가 $77.4 \%, 0.02$ 이상 $/ 0.1$ 미만이 $22.6 \%, 0.1$ 이상은 없었으며, 최종추적 관 찰 시에는 각각 $58.1 \%, 22.6 \%, 19.4 \%$ 였다 $(p=0.013)$. 혈관폐쇄 정도가 심할수록 시력회복이 제한되는 결과를 보였다 $(p=0.004)$. 결론: 중심망막동맥폐쇄를 추적 관찰한 결과 약 $45 \%$ 에서 시력회복이 나타났다. 혈관폐쇄의 정도는 장기 시력회복을 예측할 수 있는 인자였다. 